\title{
NBSIR 73.284
}

\section{Examination of United Aircraft of Canada Compressor Turbine Disk and Blade Assembly}

T. Robert Shives

Mechanical Properties Section Metallurgy Division

Institute for Materials Research

National Bureau of Standards

Washington, D. C. 20234

October 3, 1973

Failure Analysis Report

Prepared for

Bureau of Aviation Safety

National Transportation Safety Board

Department of Transportation

Washington, D. C. 20591 

NBSIR 73-284

\section{EXAMINATION OF UNITED AIRCRAFT OF CANADA COMPRESSOR TURBINE DISK AND BLADE ASSEMBLY}

T. Robert Shives

Mechanical Properties Section

Metallurgy Division

Institute for Materials Research

National Bureau of Standards

Washington, D. C. 20234

October 3, 1973

Failure Analysis Report

"This document has been prepared for the use of the Bureau of Aviation Safety, National Transportation Safety Board, Department of Transportation, Washington, D. C. Responsibility for its further use rests with that agency. NBS requests that if release to the public is contemplated, such action be taken only after consultation with the Office of Public Affairs at the National Bureau of Standards."

\section{Prepared for}

Bureau of Aviation Safety

National Transportation Safety Board

Department of Transportation

Washington, D. C. 20591

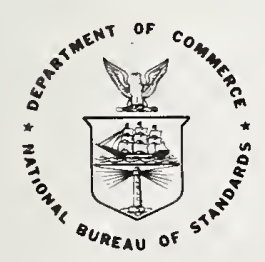

U. S. DEPARTMENT OF COMMERCE, Frederick B. Dent, Secretary

NATIONAL BUREAU OF STANDARDS, Richard W. Roberts, Director 



\section{Page}

SUMMARY

1. GENERAL INFORMATION $\ldots \ldots \ldots \ldots \ldots \ldots \ldots \ldots \ldots \ldots$

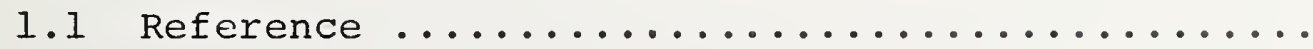

1.2 Accident Information $\ldots \ldots \ldots \ldots \ldots \ldots \ldots$

1.3 Part Submitted $\ldots \ldots \ldots \ldots \ldots \ldots \ldots \ldots \ldots$

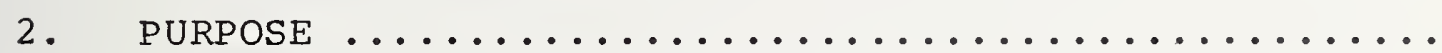

3. RESULTS OF EXAMINATIONS AND TESTS .............

3.1 Visual and Macroscopic Examination ..........

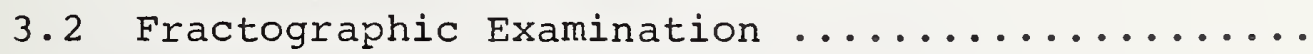

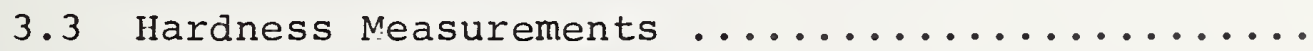

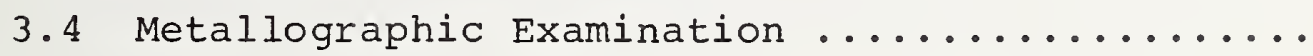

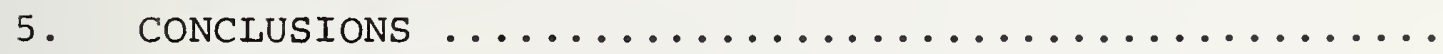

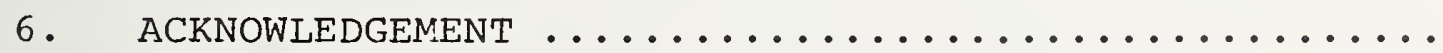

FIGURES

1. Compressor turbine disk and blade assembly as received

2. Part of the side of the turbine disk and blade

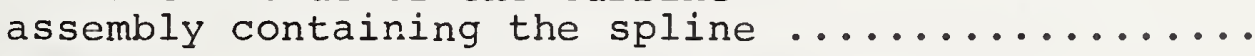

3. Part of the compressor turbine disk and blade assembly showing blade base askewness ..........

4. Part of the compressor turbine disk hub ..........

5. One of the fir trees of the disk and two blade

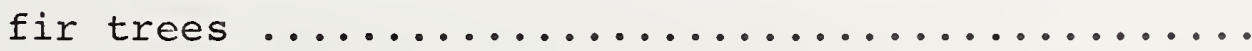

6. Fracture surfaces of the three fractured disk fir trees 



\section{FIGURES (Continued)}

7. Scanning electron photomicrograph showing

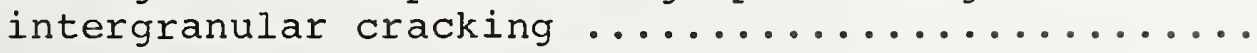

8. Scanning electron photomicrograph showing

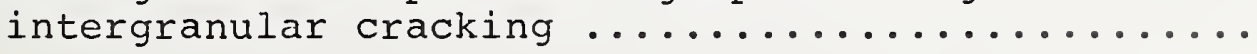

9. Scanning electron photomicrograph showing dimpled rupture

10. Circumferential section through assembly .........

11. Crack regions $A$ and $B$ from figure 10 at

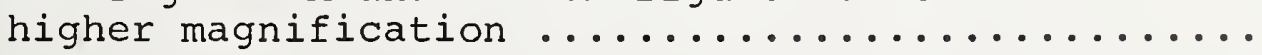

12. Etched circumferential section in crack region $B$ of one of the disk fir trees ...........

13. Etched circumferential section showing depleted zone 



\section{SUMMARY}

A damaged compressor turbine disk and blade assembly from an aircraft engine was examined primarily to determine the mode of fracture of three completely fractured disk fir trees. Cracks had initiated and propagated for some distance in an intergranular mode with the final fracture being ductile overload. In addition to the three fractured disk fir trees, the assembly had suffered considerable mechanical damage. This damage was likely caused by the assembly contacting other components of the system or a foreign object. The microstructure of the disk material appeared normal for Waspaloy in the specified heat treated condition and the hardness of the disk met specifications. A depleted zone was found at the surfaces of the disk fir trees and along the surfaces of some of the cracks in the disk fir trees. The assembly thus had apparently been subjected to the service atmosphere for a time after some of the cracks had formed. 
Examination of United Aircraft of Canada

Compressor Turbine Disk and Blade Assembly

1. GENERAL INFORMATION

1.1 Reference

Bureau of Aviation Safety, National Transportation Safety Board, Department of Transportation, Washington, D. C. Request by Mr. Michael L. Marx, dated June 8, 1973. The Bureau of Aviation Safety had been requested by the National Board of Aviation, Helsinki, Finland, to provide technical assistance in the examination of the assembly.

\subsection{Accident Information}

KAR-AIR OY DeHavilland Twin Otter DHC-6, series 200 , serial number 66. The accident occurred between oulu and Kus amo, Finland, on February 5, 1973.

\subsection{Part Submitted.}

One failed aircraft engine compressor turbine disk and blade assembly, United Aircraft of Canada, Ltd., part number 3013511, was submitted for examination. Three fir tree regions of the disk had fractured and separated from the assembly. The separated parts of the disk and the blades which had been attached to them were not submitted, except for a small piece of one blade which remained attached to the assembly (arrow $A$, figure 1).

\section{PURPOSE}

The Bureau of Aviation Safety requested the NBS Mechanical Properties section to document the damage to the disk, perform a fractographic examination of the three fractured fir tree areas of the disk, perform a metallographic examination of the disk material, and make hardness measurements on the disk material.

\section{RESULTS OF EXAMINATIONS AND TESTS}

3.1 Visual and Macroscopic Examination

Every blade of the compressor turbine disk and blade assembly had been fractured, with the possible exception of two missing blades which had been attached to the fractured fir tree part of the disk. A number of the fractured blades 

can be seen in figures 1 and 3. In general, the fractures occurred so that the outermost part of the blades remaining in the assembly ranged from about $1 / 16$ to $1 / 4$ inch beyond the top of the blade base (arrows B, figures 1 and 3 ). One blade (arrow A, figure 1) had fractured near the base of the disk fir trees. This was in the region of the disk where three of the disk fir trees had fractured. A few of the blade fracture surfaces exhibited rather severe mechanical damage (arrow $C$, figures 1 and 3), apparently having been caused by relative circumferential motion between the blades and either another compressor part or a foreign object. Except for those which had suffered mechanical damage, the fracture surfaces of the blades were dark gray in color.

Both sides of the disk were discolored. The portion between the ring containing the balancing weights and the disk hub ranged from light blue near the balancing weight ring to no apparent discoloration at the hub. Discoloration in this area was greater on the side of the disk opposite to that containing the spline. The regions between the balancing weight ring and the outside of the disk were discolored about equally on both sides. The coloring ranged from light blue near the ring through straw, violet, green, and back to straw. The fir tree regions of the disk and the blades were dark gray in color.

About $1 / 3$ of the circumference of the outside of the balancing weight ring on the side of the disk containing the spline had been roughened by circumferential rubbing. Part of this damage can be seen in figure 1 (arrow D).

The neads of all the rivets and the sides of all the disk fir trees on the side of the disk containing the spline had suffered mechanical damage by apparent circumferential rubbing. Many of the blade fir trees also suffered similar damage. Examples of this fir tree and rivet damage are shown in figure 2. The severest damage to the sides of the disk fir trees was found in about $1 / 3$ of the disk circumference. About $2 / 3$ of the more severely damaged area was in the same $1 / 3$ of the disk which contained the damage to the balancing weight ring discussed above. Many of the blade bases were askew as can be seen in figure 3. This was probably caused either by the rubbing action or contact of the blades with another component or foreign object. Some of the blade bases were somewhat loose on the fir tree assemblies and could be moved slightly. 
There was a line of fretting damage which traversed between $1 / 4$ and $1 / 3$ of the circumference of the disk hub between the spline and the end of the hub (figure 4). This damage was located essentially opposite to the damage to the balancing weight ring.

Every disk fir tree was cracked in at least two places, and possibly three. An example of these cracked regions is shown in figure 5. One of the cracked regions, indicated by $A$, is in the first root from the top of the fir tree. The second cracked region, indicated by $B$, figure 5 , is on the opposite side of the fir tree in the second root from the top. Many, and perhaps all, of the fir trees were cracked in a third region designated $\mathrm{C}$ in figure 5. There was considerable mechanical damage in this area of the trees and it was not possible to determine in all cases whether a crack was present without some preparation of the surface (which did not appear to be warranted). Cracks in other areas of some of the disk fir trees were noted. In the tree shown in figure 5 , the cracks in region $B$ appear to be propagating toward those in regions $A$ and $C$, and conversely, cracks in regions $A$ and $C$ appear to be propagating toward those in region $B$.

Three of the disk fir trees had fractured completely. The fracture surfaces of these fir trees are shown in figure 6. Fracture 1 had occurred across the tree through region $C-C^{\prime}$, fracture 2 through region $B C$, and fracture 3 through region $A-A^{\prime}$, figure 5 .

\subsection{Fractographic Examination}

The fracture surfaces of the three fractured fir tree sections of the disk were blue in color in some areas (primarily near the centers) and dark gray in others (primarily near the leading and trailing edges as the disk would rotate in service). The three fracture surfaces were examined with the scanning electron microscope (SEM). Before the examination, the surfaces were cleaned in an ultrasonic bath with water and detergent. This cleaning treatment did not remove the discoloration from the surfaces indicating that it was apparently not of a superficial nature.

The SEM examination revealed intergranular cracking as the principal mode of fracture in the apparent crack initiation areas on both leading and trailing edges (as the disk would rotate in service) of fractures 1 (location $C-C^{\prime}$, figure 5) and 2 (location $B C$, figure 5) and on one side of fracture 3 (location $A-A^{\prime}$, figure 5). The cracks propagated in an 

intergranular mode for varying distances up to one half the width of the fir tree before the fracture was completed by ductile overload, as evidenced by dimpled rupture as the principal fracture feature. Representative examples of the intergranular cracking are shown in figures 7 and 8 , and $a$ representative example of dimpled rupture in an overload region is shown in figure 9. Figure 8 appears to exhibit some corrosion product. The dark gray areas of the fracture surfaces exhibited the intergranular cracking and the blue areas exhibited dimpled rupture.

\subsection{Hardness Measurements}

Knoop microhardness measurements (KHN) at a load of 500 grams were made on a circumferential section through some of the cracked disk fir trees. The KHN500 hardness ranged from 352 to 394. The approximate Brinell equivalent hardness values ranged from BHN 332 to 362 which is well within the requirements of United Aircraft of Canada in-house specification CPW 203 which called for a Brinell hardness within the range of 313 to 403 , or equivalent.

\subsection{Metallographic Examination}

A circumferential section through several of the disk fir trees was examined metallographically. A low magnification photograph showing parts of the fir tree portions of two blades (top left and top right in the figure), parts of two rivet heads, and parts of two of the disk fir trees is shown in figure 10 with the specimen unetched. Several cracks can be seen, including the cracks in regions $A, B$, and $C$, figure 5. These crack regions are again indicated by $A, B$, and $C$ in figure 10. The dark areas in the photomacrograph are filled with mounting material, hence the only parts of the section that show are those in the plane that has been polished. The area containing crack regions $A$ and $B$ is shown at higher magnification in figure 11. There is considerable deformation in the region between the crack regions, and it can be seen that the cracks in the two regions appear to be propagating toward each other.

A higher magnification photomicrograph of one of the cracked regions (figure 12) shows that the cracks are intergranular in nature as indicated by the fractographic examination of the fractured fir trees. The microstructure consists of carbide particles in a gamma matrix and appears to be free of stringers. A fairly thin region near the surface of the tree is outlined in figure 12. This is a zone 

apparently caused by reaction of the material of the disk with the service atmosphere at elevated temperatures, and is referred to by the manufacturer as a depleted zone. This depleted zone was found along the walls of some of the cracks in some places, an example of which is shown in figure 13.

\section{DISCUSSION OF RESULTS}

The discoloration of parts of the compressor turbine disk assembly was apparently caused by subjecting the assembly to high temperatures, but since the assembly is expected to operate at elevated temperatures, the discoloration is likely a consequence of normal operation.

The fractured blades and disk fir trees, the fretted hub, and the rubbing damage to the sides of the disk fir trees, the sides of the blade fir trees, the rivet heads, and the balancing weight ring indicate that the disk assembly was in contact with either another component(s) of the engine or a foreign object. It may be possible trat some of the fractured blade fragments caused some of the damage to the sides of the disk fir trees. The cracks in the fir tree areas of the disk may have been caused by stresses transmitted to them through the blades when the blades were in contact with other components or a foreign object, or by overstressing in operation.

Both fractographic and metallographic examinations indicated that the cracks in the fir trees propagated initially in an intergranular mode. For the three disk fir trees which had completely fractured the final rupture occurred in ductile overload. The discoloration of the fracture surfaces indicates that the assembly was probably subjected to high temperatures after the cracks had propagated to fracture, although the speed at which the cracks propagated is not known.

The depleted zone which appeared along the surface of the fir tree portions of the disk (and perhaps elsewhere at the disk surface) was apparently caused by a reaction of the disk material to the service atmosphere. The fact that the depleted zone appeared along some of the fir tree cracks indicated that these cracks had been in existence with the assembly in service long enough for the zone to form.

Nothing unusual was noted in the microstructure of the disk material. The microstructure consisted of carbide particles in a gamma matrix, which is normal for waspaloy in the heat treated condition called for in United Aircraft of Canada Specification CPW 203. 

The results of the hardness measurements indicated that the disk material met the hardness requirements as set forth in United Aircraft of Canada Specification CPW 203.

\section{CONCLUSIONS}

1. The extensive damage to the compressor turbine disk and blade assembly was apparently caused by contact of the assembly with other components of the system or with a foreign object.

2. The discoloration of the disk surface appeared to be due to exposure to high temperatures and is likely a consequence of normal operation.

3. Cracks were found in all the disk fir trees. They probably were caused by stresses transmitted to them through the blades when the blades were in contact with other system components or a foreign object.

4. The fractures in the three completely fractured disk fir trees initiated and propagated some distance in an intergranular mode before final failure occurred in ductile overload.

5. A depleted zone along some of the disk fir tree crack surfaces indicates that the assembly was probably in the service atmosphere for some time after those cracks formed. A depleted zone was also found at the surfaces of the disk fir trees.

6. The microstructure appeared normal for Waspaloy in the prescribed heat treatment.

7. The hardness of the disk material met United Aircraft of Canada Specification CPW 203.

\section{ACKNOWLEDGEMENT}

Mr. L. C. Smith of the NBS Mechanical Properties Section prepared the specimens for the metallographic and fracto-graphic examinations and performed the hardness measurements. 




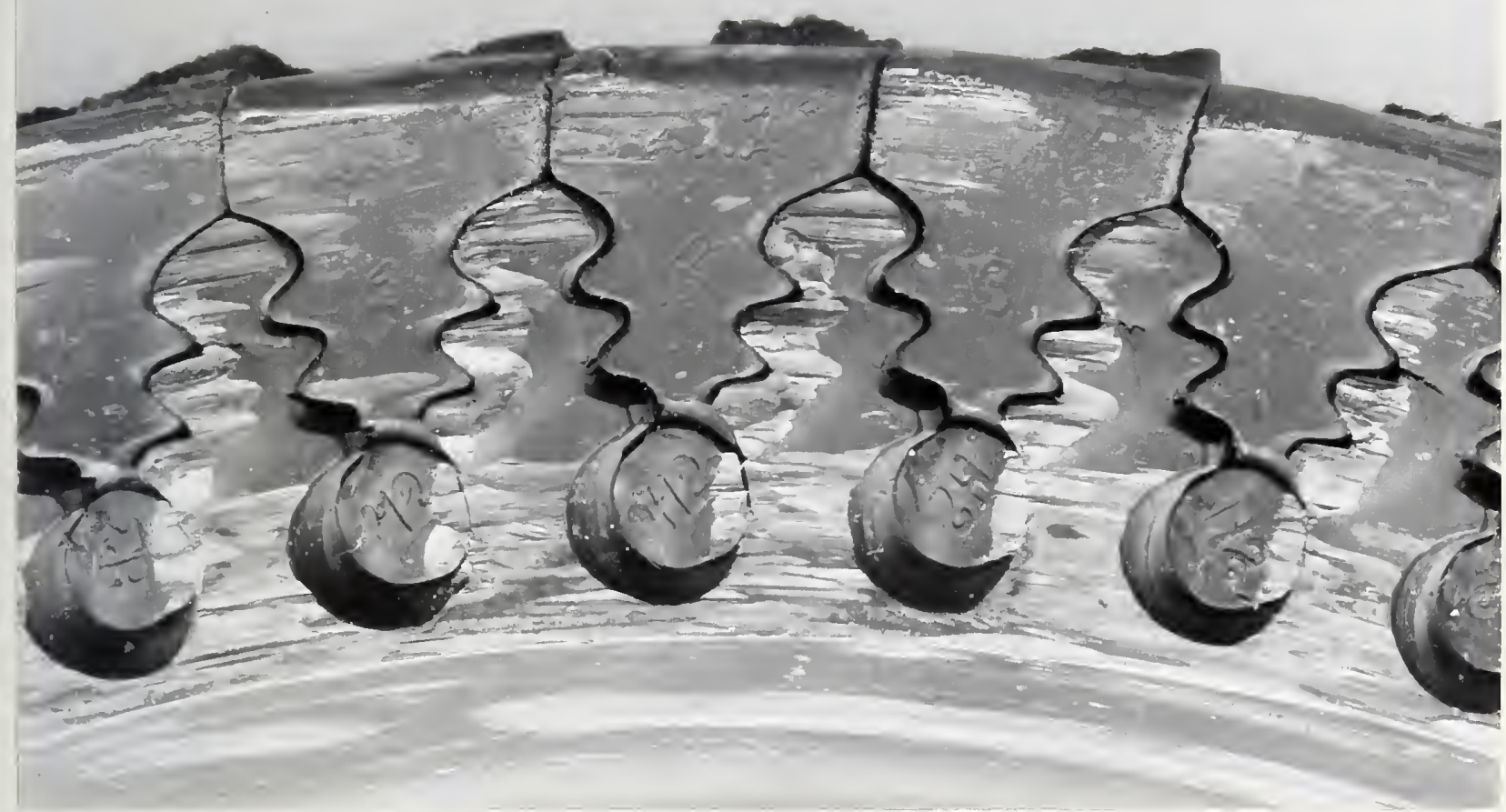

Figure 2. Part of the side of the turbine disk and blade assembly containing the spline showing circumferential rubbing damage to the rivet heads and to the fir tree areas of the disk and blades. $\times 4$

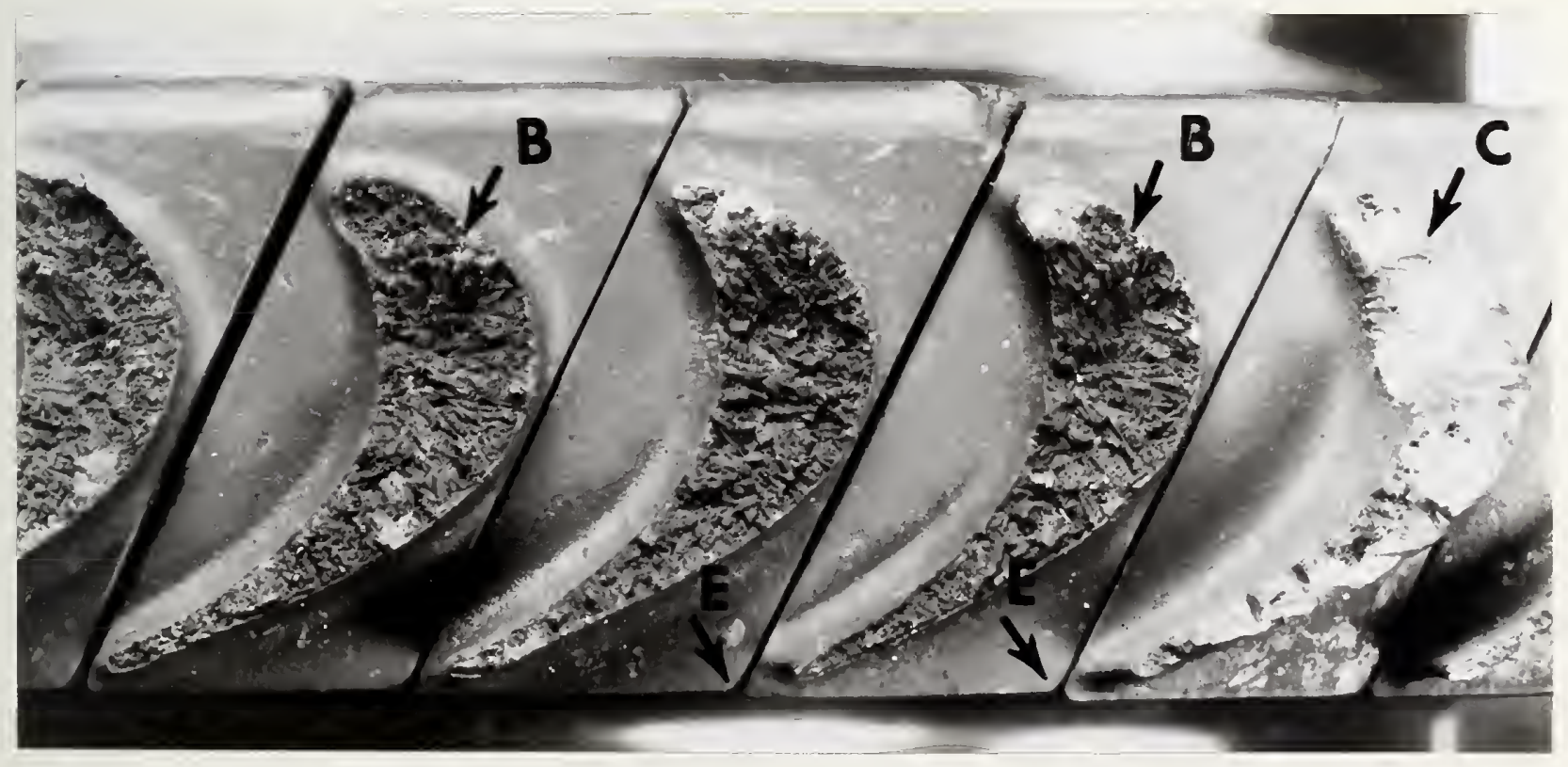

Figure 3. Part of the compressor turbine disk and blade assembly showing blade base askewness (arrows $\mathrm{E}$ ) and the fracture surfaces of several blades. Arrows B indicate fractures representative of most of the blades. Arrow $C$ indicates a blade fracture surface exhibiting severe mechanical damage. $\times 4$ 


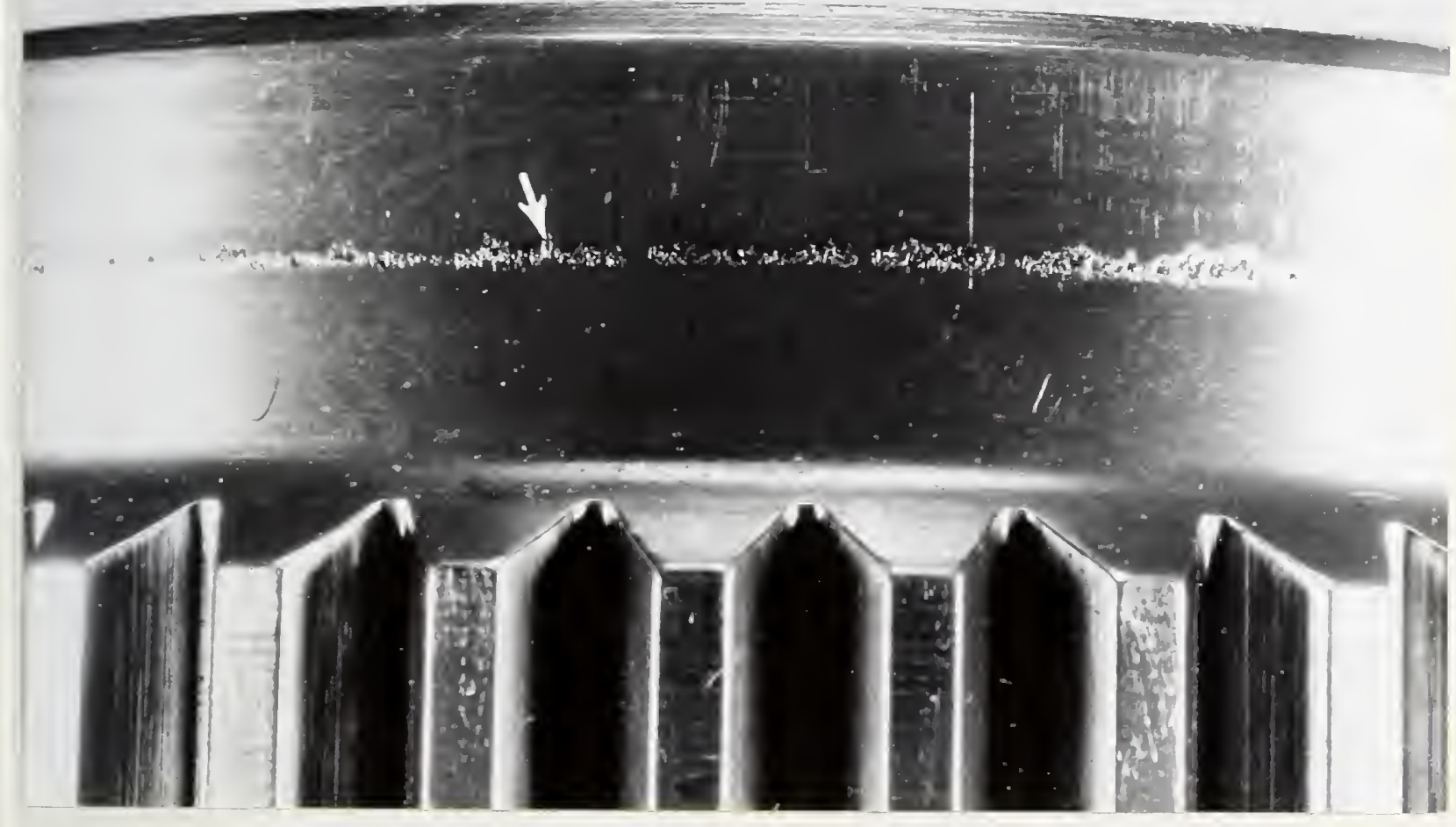

Figure 4. Part of the compressor turbine disk hub between the spline and the end of the hub showing fretting damage (indicated by arrow). X 10 



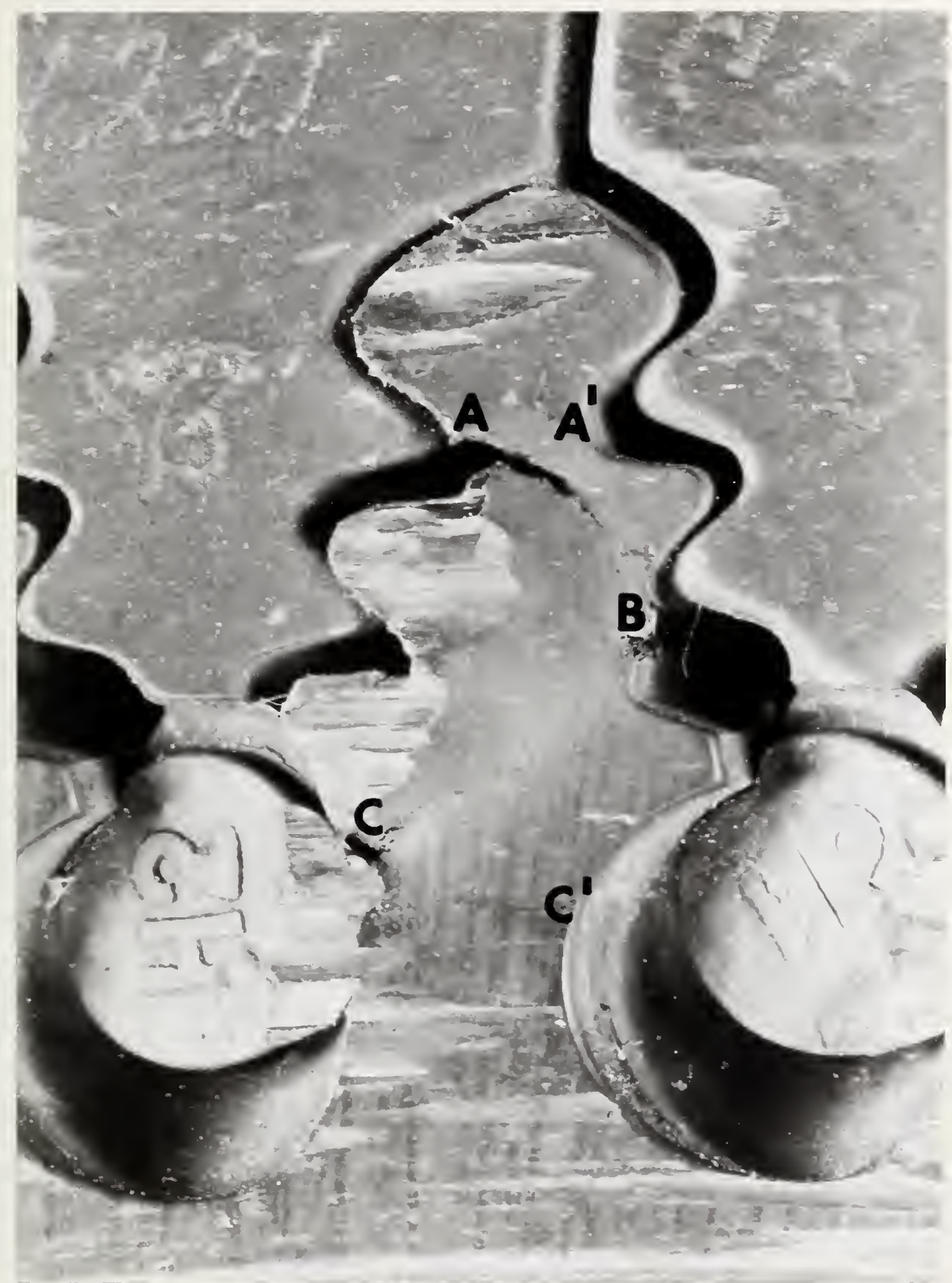

Figure 5. One of the fir trees of the disk (center) and two blade fir trees. The regions of crack initiation in the disk fir trees are indicated by $A, B$, and $C$. Of the three fir trees which had fractured, the fracture crack passed through $A-A^{\prime}$, in one, through $B-C$ in one, and through $C-C$ ' for the other. $\times 10$ 



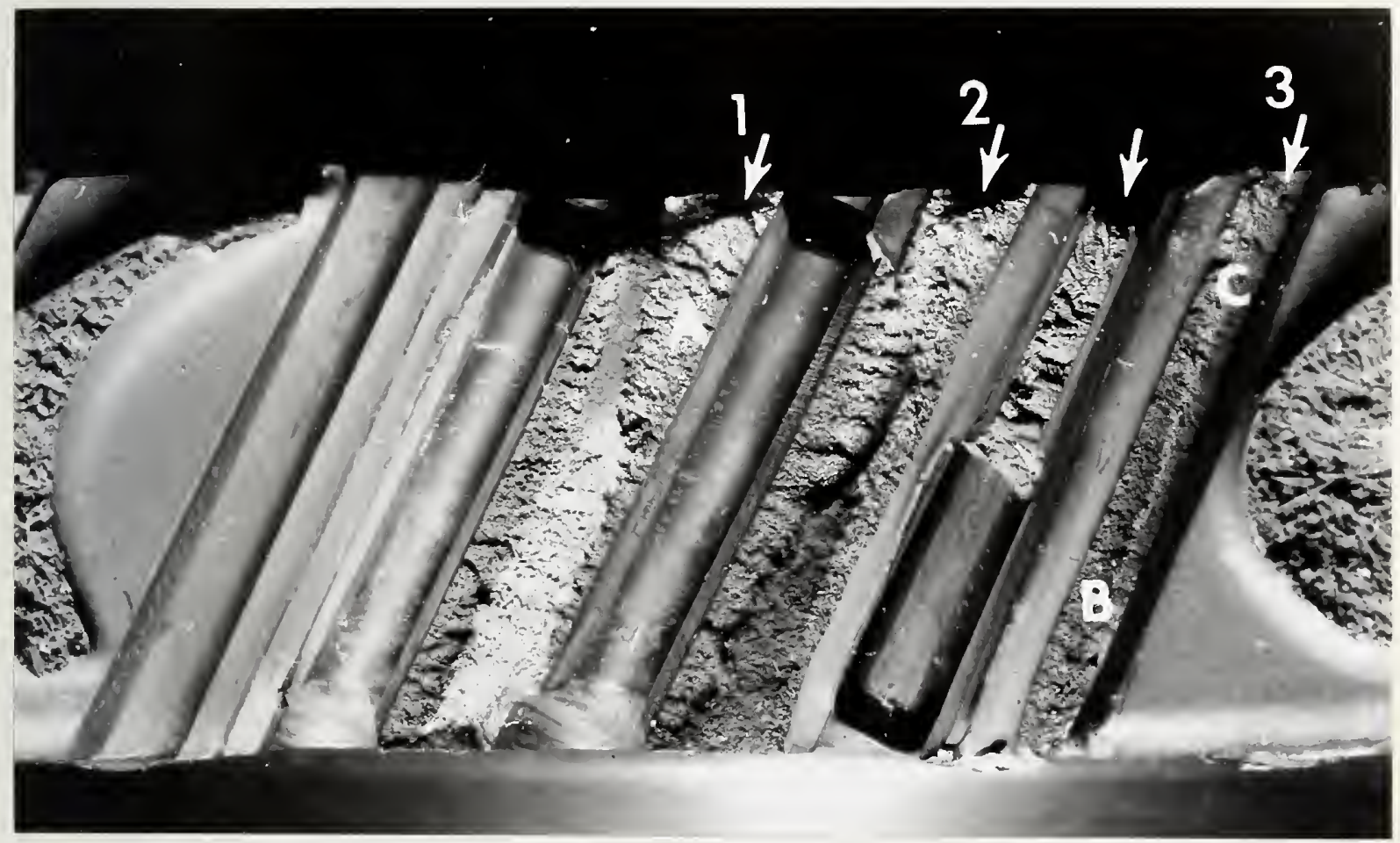

Figure 6. Fracture surfaces of the three fractured disk fir trees, indicated by arrows 1,2 , and 3 . Part of one of the blade fir trees which had fractured and remained attached to the disk is indicated by the unmarked arrow. The locations of the scanning electron photomicrographs shown in figures 7,8 , and 9 are indicated by $A, B$, and $C$, respectively. $X 4$ 


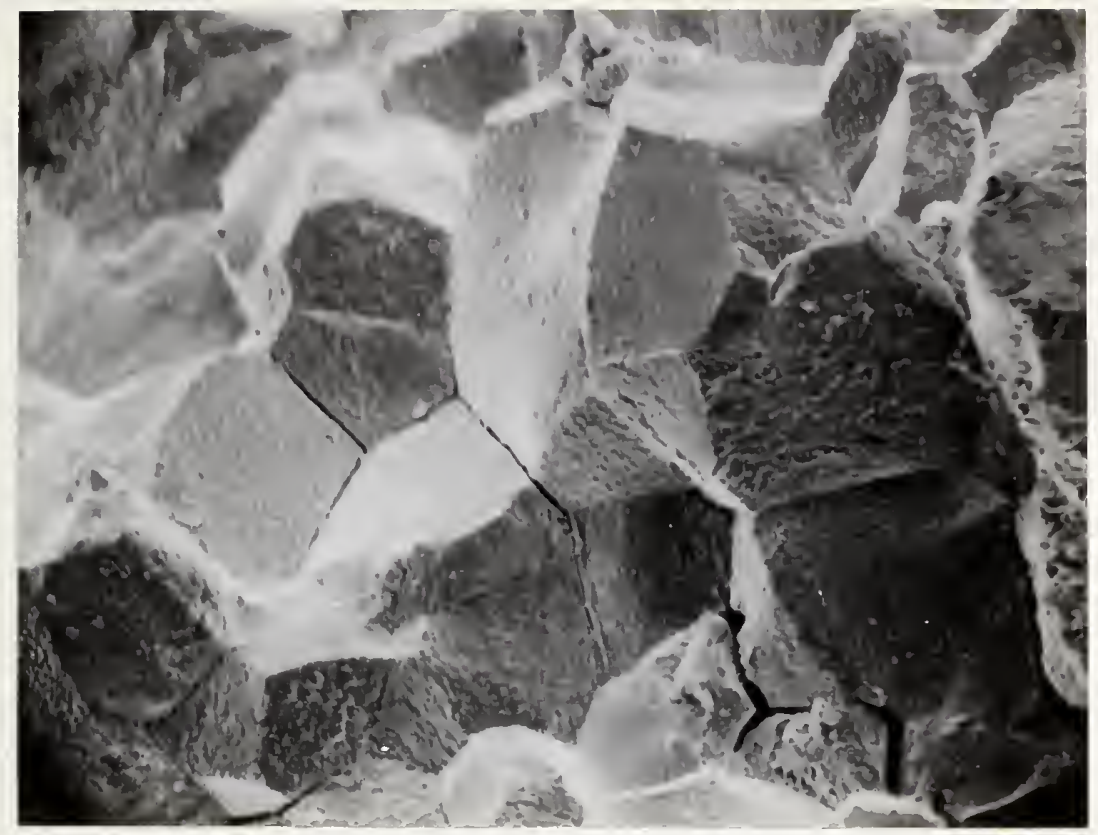

Figure 7. Scanning electron photomicrograph showing intergranular cracking. The area shown was located approximately at $A$ on fracture 1, figure 6. This is representative of the fracture features exhibited by the dark gray areas of the fracture surfaces. X 520

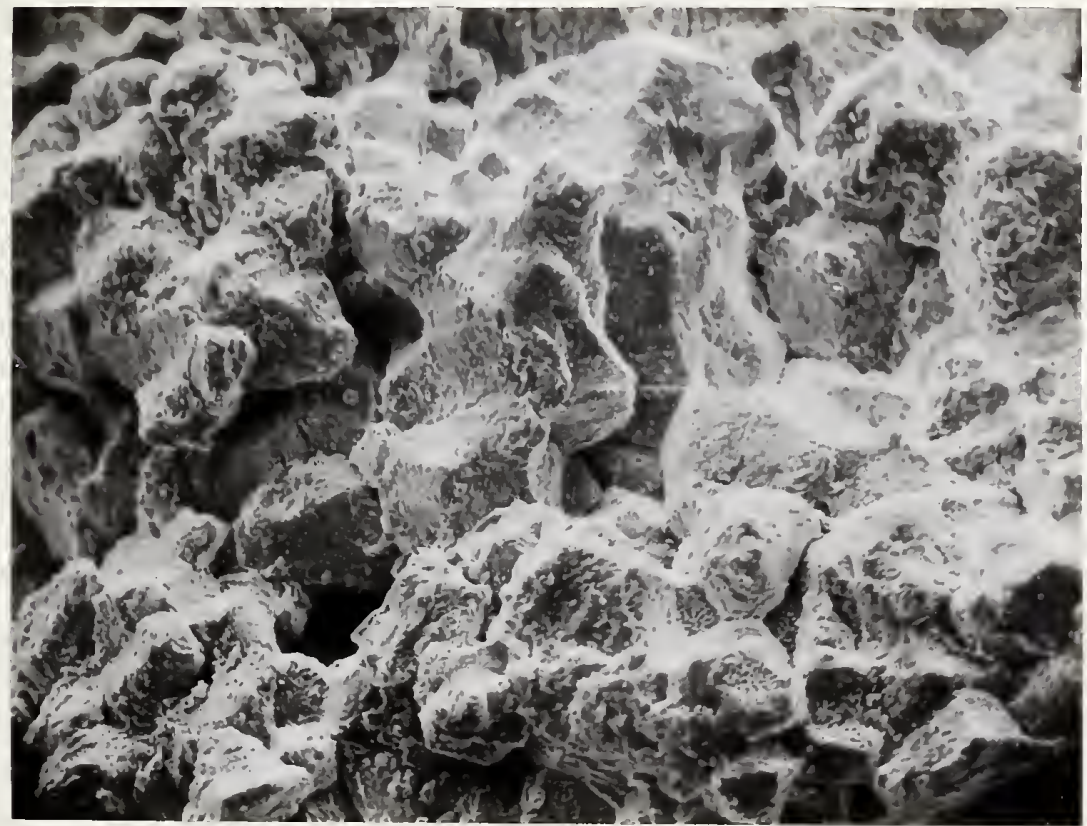

Figure 8. Scanning electron photomicrograph showing intergranular cracking. There appears to be some corrosion product here. The area shown was located approximately at $B$ on fracture 3, figure 6. X 330 




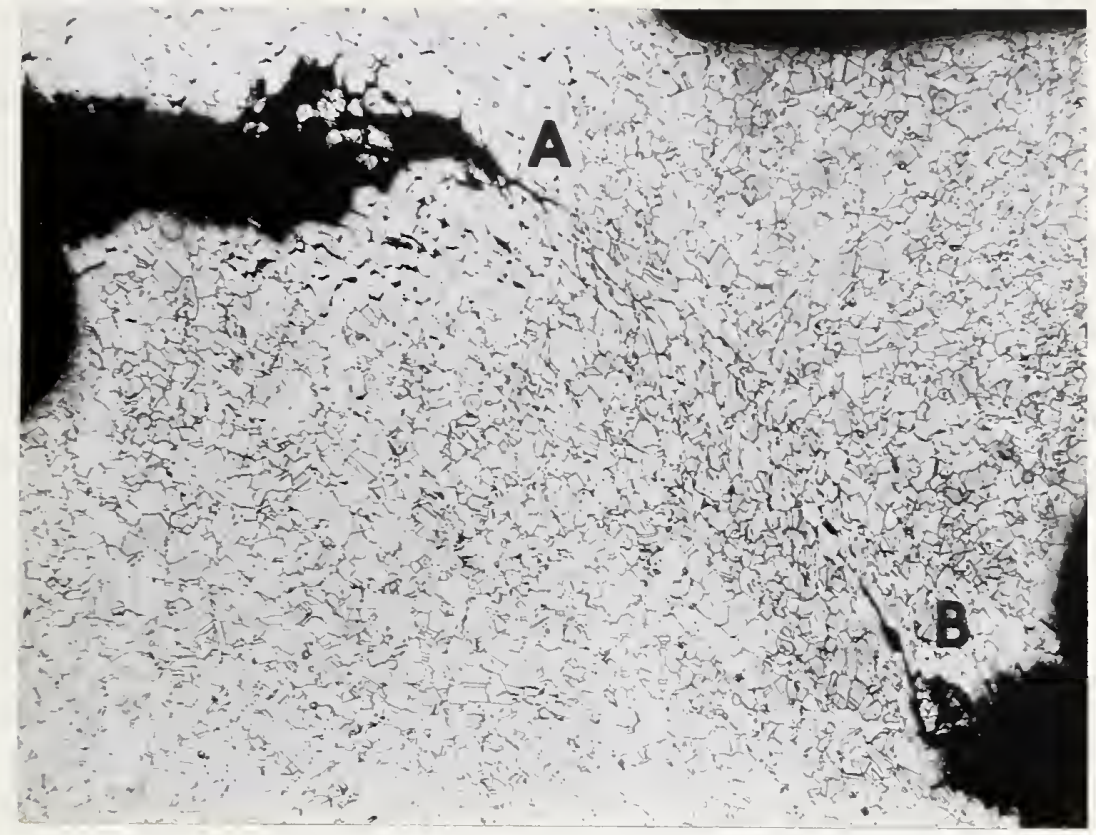

Figure 11. Crack regions $A$ and $B$ from figure 10 at higher magnification. Section was etched to show the deformation in the material between the two cracked regions. Etch: Kalling's. X 40

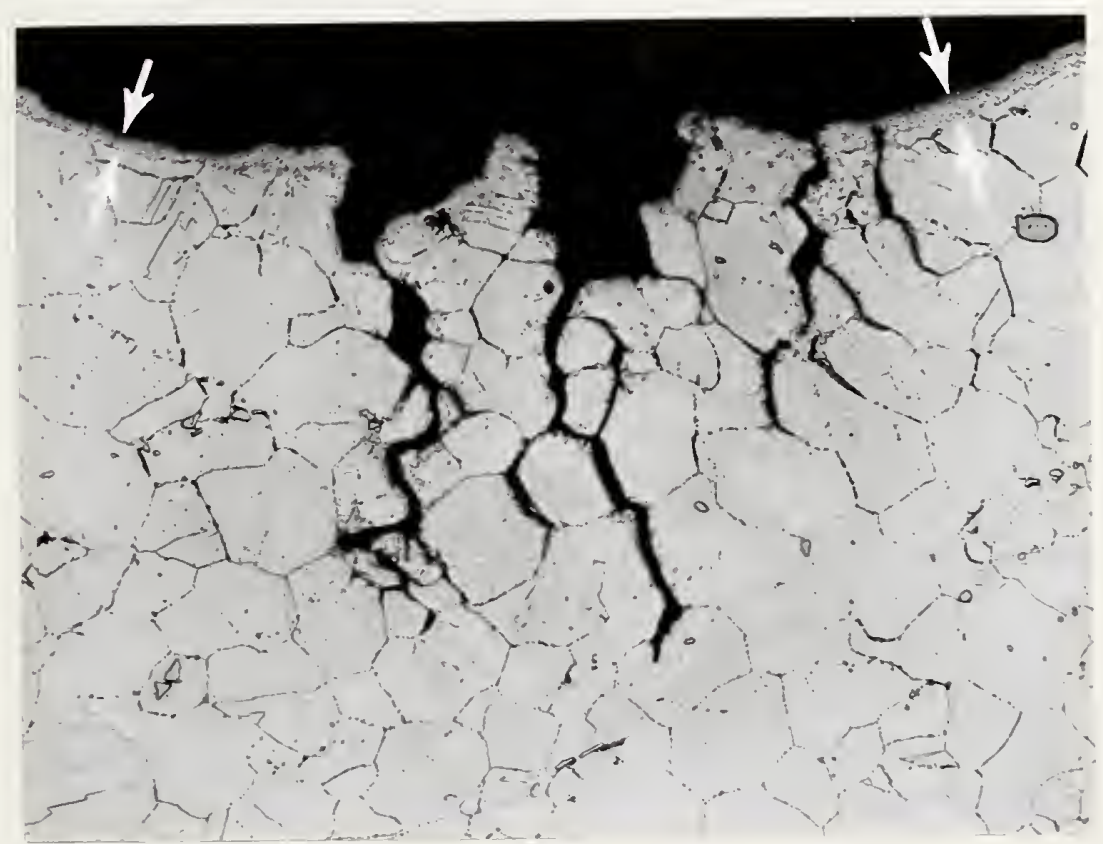

Figure 12. Etched circumferential section in crack region $B$ of one of the disk fir trees. The intergranular nature of the cracks is evident. A narrow region near the surface of the tree (indicated by arrows) termed a depleted zone can be seen.

Etch: Kalling's. $\times 200$ 



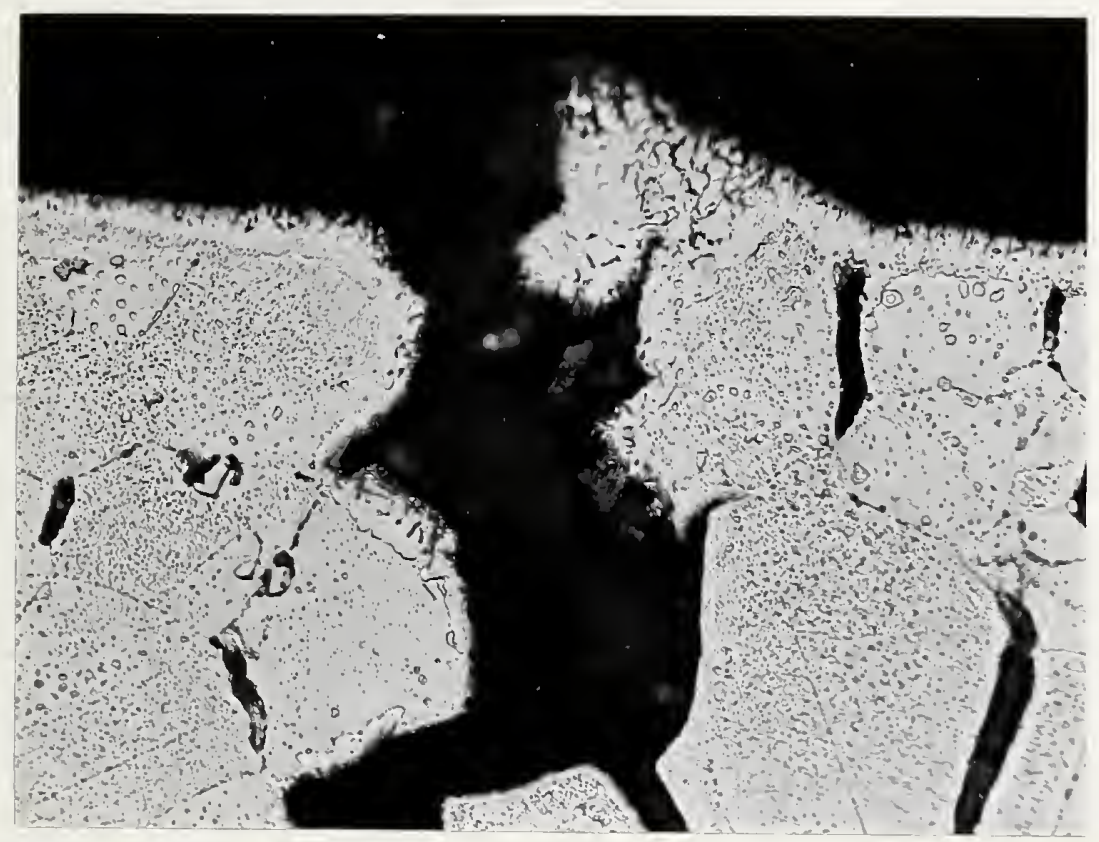

Figure 13. Etched circumferential section showing depleted zone along part of the crack wall as well as along the surface of the tree.

Etch: Kalling's. X 500 
. 


